\title{
Prediction of complications and death in octogenarians with left main coronary artery disease after coronary artery bypass implantation - off-pump, on-pump and minimally invasive techniques comparison
}

\author{
Anetta Kowalczuk-Wieteska ${ }^{1}$, Monika Parys ${ }^{1}$, Rafał Pawlaczyk², Krzysztof Filipiak ${ }^{3}$, Marek Cisowski ${ }^{4}$, \\ Andrzej Bochenek ${ }^{4}$, Zdzisław Tobota ${ }^{4}$, Bohdan Maruszewski ${ }^{5}$, Michał Zembala ${ }^{1}$, Marian Zembala ${ }^{1}$ \\ ${ }^{1}$ Department of Cardiac Surgery, Transplantology, Vascular Surgery and Endovascular, Medical University of Silesia, Silesian Center \\ for Heart Diseases, Zabrze, Poland \\ 2Department of Cardiovascular Surgery, Medical University of Gdansk, Gdansk, Poland \\ ${ }^{3}$ Cardiac Surgery Clinic, Independent Public Clinical Hospital No. 2, Pomeranian Medical University, Szczecin, Poland \\ ${ }^{4}$ First Department of Cardiac Surgery, American Heart of Poland, Bielsko-Biala, Poland \\ Institute “Memorial - Children's Health Center", Warsaw, Poland
}

Adv Interv Cardiol 2019; 15, 2 (56): 218-225

DOI: https://doi.org/10.5114/aic.2019.86015

\begin{abstract}
A bstract
Introduction: Off-pump coronary artery bypass grafting is considered potentially more effective than on-pump surgery in elderly patients.

Aim: To compare the early and long-term results of these techniques in patients $\geq 80$ years of age with left main coronary artery disease.

Material and methods: All patients $\geq 80$ years of age $(N=3648)$ who were reported to the Polish National Registry of Cardiac Surgery Procedures between 2006 and 2016 and underwent primary, isolated coronary artery bypass surgery were included in the study. The patients were divided into 2 groups: group A - without significant left main stenosis (LMS) $(n=2094)$ and B group - with LMS $\geq 50 \%(n=1524)$. The groups were compared according to the type of surgery: on-pump $(A=1107$ vs. $B=891)$, off-pump $(A=$ 908 vs. $B=616)$ and $\operatorname{MIDCAB}(A=79$ vs. $B=17)$.

Results: There were significant differences in preoperative status between the groups in the whole cohort, which were not observable after propensity score matching. The in-hospital mortality was significantly higher in the LMS group operated on-pump $(10.5 \%$ vs. $7.0 \% ; p=0.01)$ and non-significant in the off-pump group ( $5.1 \%$ vs. $5.7 \% ; p=0.78)$, as well as in the MIDCAB subgroup $(5.9 \%$ vs. $5.1 \%$; $p=0.64)$. 10-year survival in all subgroups was comparable and remained at a level of $50-60 \%$. The mean entire cohort follow-up was $3.4 \pm 2.7$ vs. $3.7 \pm 2.8$ years $(p=0.2)$.

Conclusions: Off-pump coronary bypass grafting may optimize the outcomes in elderly patients with significant left main stenosis. Octogenarians surgically treated for coronary artery disease, despite increased post-operative risks, present encouraging long-term survival.
\end{abstract}

Key words: octogenarians, left main disease, coronary artery bypass.

Su m m a ry

Choosing the right method of revascularization in elderly patients with left main coronary artery disease is not an easy task, especially in the absence of randomized multicentre trials in the 80+ group. In the case of 80-year-olds burdened with many diseases, the decision should be taken by the Heart Team, which includes an interventional cardiologist, a cardiac surgeon, an anaesthesiologist, but also a neurologist, diabetologist or geriatrician. Off-pump coronary bypass grafting may optimize the outcomes in elderly patients with significant left main stenosis. Octogenarians surgically treated for coronary artery disease, despite increased postoperative risks, present encouragingly long-term survival.

\section{Corresponding author:}

Anetta M. Kowalczuk-Wieteska MD, PhD, Department of Cardiac Surgery, Transplantology, Vascular Surgery and Endovascular, Medical University of Silesia, Silesian Center for Heart Diseases, 9 M. Curie-Skłodowskiej St, 41-800 Zabrze, Poland, phone: +48 692645752 , e-mail: kowaletta@onet.eu

Received: 13.10.2018, accepted: 6.01.2019. 


\section{Introduction}

In recent years, there has been an increase in the number of older people referred for the surgical treatment of cardiovascular disease and especially ischemic heart disease. This is due to the prolonged average life expectancy of the population as well as greater accessibility to diagnostic tests, especially coronary angiography. On the other hand, the development of surgical techniques and the improvement of perioperative care are conducive to reducing the risk of complications and the risk of death in each group of patients. This also applies to the patients in the ninth decade of life, who are an increasing group of patients that undergo surgery. The patient's age alone is no longer a contraindication to surgical treatment; however, the risk of death and postoperative complications in this group of patients seems to be higher in comparison to younger age groups. It is related to changes in the circulatory system because of the aging process and more frequent occurrence of comorbidities. The most frequent accompanying diseases in the group of older patients are: arterial hypertension, type 2 diabetes, chronic obstructive pulmonary disease (COPD), peripheral atherosclerosis, renal failure, and neurological diseases. Therefore, the qualification for surgery includes all aggravating factors, and individually assesses the risk of surgery and potential benefits [1-4].

According to the European Society of Cardiology (ESC)/European Association for Cardio-Thoracic Surgery (EACTS) guidelines from 2014, heart revascularisation patients with significant stenosis of the left main artery are potential candidates for coronary artery bypass grafting. In Poland, in all cardiosurgery departments, the proportion of octogenarians with coronary artery disease increased from 2006 to 2016 from $48 \%$ to $61 \%$, including LMS at a constant level of $44 \%$ (Figure 1 ).

\section{Aim}

The study aimed to compare the early and long-term results of off-pump, on-pump and minimally invasive techniques in patients $\geq 80$ years of age with left main coronary artery disease and on the basis of results analysis, selecting the safest operating technique for octogenarians [1].

\section{Material and methods}

\section{Data source}

The National Registry of Cardiac Surgery (Krajowy Rejestr Operacji Kardiochirurgicznych - KROK) is the database of all cardiac operations performed in Poland. It has been functioning in its present form since 2005. Data transfer to the KROK is mandatory and guaranteed by an agreement between the centres and the Polish Ministry of Health. The KROK collects data on the preoperative status of patients, risk factors, operative methods, perioperative course and early outcomes. Long-term, all-cause mortality data were obtained from the national death registry, after checking the patients' Personal Identification Number.

\section{The study population}

The population of Poland is over 38 million and about 26000 cardiac operations are performed annually. Between 2006 and 2016, more than 100000 operations were performed for coronary artery disease. The patients who underwent primary, isolated coronary artery bypass surgery $(C A B G)$ during this period, and had records indicating preoperative left main significant stenosis, were included in the analysis.

The lack of some data in selected patients did not allow for proper propensity score (PS) matching. Based on the Polish database KROK, the study covered $n=3648$ patients $>80$ years old. Two subgroups have been isolated. Subgroup A, $n=2094$ (81.9 \pm 2.0 years) - without significant stenosis of the left main coronary artery (LM), and subgroup $B, n=1524$ (82.2 \pm 2.2 years) - with LM stenosis $\geq 50 \%$ (Table I). Octogenarians subjected to minimally invasive direct coronary artery bypass (MIDCAB) are a small group of patients, operated on due to a significant reduction in left anterior descending (LAD) $(n=$ 79 ) in patients without left main stenosis (LMS) and LMS with proximal LAD $(n=17)$. These patients were not subjected to coronary angioplasty of other coronary vessels.

The early outcomes included in-hospital mortality and the occurrence of perioperative myocardial infarction, postoperative intra-aortic balloon pumping (IABP), haemodiafiltration, and re-sternotomy due to postoperative bleeding. The lengths of intensive care unit (ICU) and overall hospital stay were also assessed. The long-term survival was compared between the groups, without differentiation between the causes of death.

In terms of preoperative burden, such as lipid disorders, hypertension, diabetes, chronic renal failure, COPD, carotid and lower limbs atherosclerosis, the two subgroups presented a comparable frequency (Table I-IV).

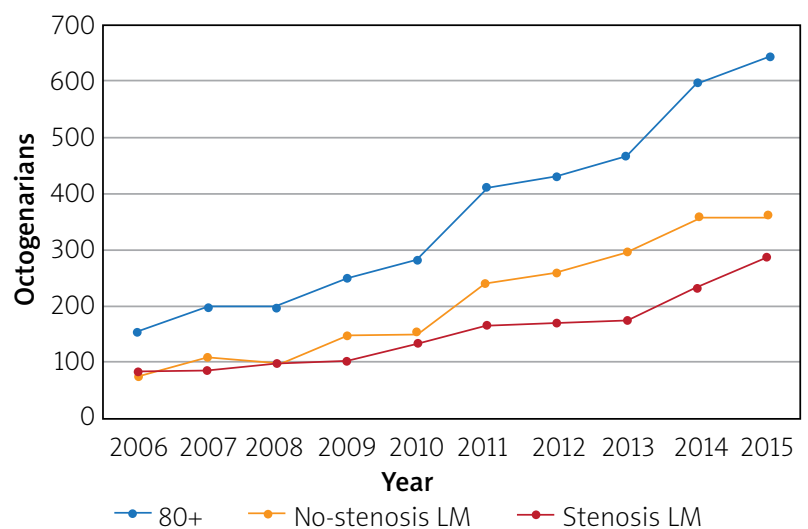

Figure 1. Numbers of octogenarians with no-LMS vs. LMS treated with cardiac surgery due to coronary heart disease 
Table I. All patients

\begin{tabular}{|c|c|c|c|}
\hline Parameter & $\begin{array}{c}\text { No-LMS } \\
(n=2108)\end{array}$ & $\begin{array}{c}\text { LMS } \\
(n=1540)\end{array}$ & $P$-value \\
\hline Age & $81.9 \pm 2.0$ & $82.2 \pm 2.2$ & $<0.001$ \\
\hline Male sex & $62 \%$ & $67 \%$ & $<0.001$ \\
\hline EF (\%) & $49.9 \pm 10.3$ & $48.2 \pm 11.3$ & $<0.001$ \\
\hline EuroSCORE & $3.1 \pm 3.7$ & $4.2 \pm 6.1$ & $<0.001$ \\
\hline CCSI & $8.8 \%$ & $4.8 \%$ & $<0.001$ \\
\hline $\operatorname{cCS} \|$ & $32.1 \%$ & $22.5 \%$ & $<0.001$ \\
\hline CCS III & $43.8 \%$ & $41.7 \%$ & 0.22 \\
\hline CCS IV & $15.3 \%$ & $31.0 \%$ & $<0.001$ \\
\hline NYHA I & $42.1 \%$ & $37.2 \%$ & 0.003 \\
\hline NYHA II & $43.0 \%$ & $40.4 \%$ & 0.13 \\
\hline NYHA III & $13.4 \%$ & $17.4 \%$ & $<0.001$ \\
\hline NYHA IV & $1.5 \%$ & $5.0 \%$ & $<0.001$ \\
\hline BMI & $26.9 \pm 3.7$ & $26.7 \pm 4.2$ & 0.04 \\
\hline Previous MI & $64 \%$ & $70 \%$ & $<0.001$ \\
\hline Previous PCl & $23 \%$ & $17 \%$ & $<0.001$ \\
\hline Smoking & $42 \%$ & $43 \%$ & 0.44 \\
\hline Diabetes & $34 \%$ & $33 \%$ & 0.44 \\
\hline Arterial hypertension & $90 \%$ & $89 \%$ & 0.32 \\
\hline Hyperlipidaemia & $57 \%$ & $58 \%$ & 0.83 \\
\hline Renal insufficiency & $47 \%$ & $44 \%$ & 0.16 \\
\hline COPD & $6 \%$ & $8 \%$ & 0.14 \\
\hline Atrial fibrillation & $11 \%$ & $10 \%$ & 0.40 \\
\hline CVD & $40 \%$ & $44 \%$ & 0.26 \\
\hline PVD & $92 \%$ & $93 \%$ & 0.85 \\
\hline Intravenous NTG/heparin & $13 \%$ & $25 \%$ & 0.00 \\
\hline Inotropic support & $1.7 \%$ & $13.5 \%$ & 0.00 \\
\hline Mechanical ventilation & $0.2 \%$ & $0.5 \%$ & 0.15 \\
\hline Cardiogenic shock & $0.6 \%$ & $1.7 \%$ & 0.00 \\
\hline Preoperative IABP & $1.9 \%$ & $3.9 \%$ & 0.00 \\
\hline $\begin{array}{l}\text { No. of narrowed coronary } \\
\text { arteries }\end{array}$ & $2.3 \pm 0.9$ & $2.4 \pm 0.8$ & 0.00 \\
\hline No. of venous grafts & $1.4 \pm 0.9$ & $1.6 \pm 0.9$ & 0.00 \\
\hline No. of arterial grafts & $0.9 \pm 0.5$ & $0.8 \pm 0.5$ & 0.00 \\
\hline In-hospital mortality & $6.1 \%$ & $9.1 \%$ & 0.001 \\
\hline Bleeding (reoperation) & $5.4 \%$ & $6.3 \%$ & 0.29 \\
\hline Perioperative MI & $1.3 \%$ & $1.6 \%$ & 0.55 \\
\hline Haemodiafiltration & $3 \%$ & $4.5 \%$ & 0.02 \\
\hline Postoperative IABP & $3 \%$ & $6.6 \%$ & 0.00 \\
\hline Multiorgan complications & $1.8 \%$ & $3.8 \%$ & 0.00 \\
\hline Neurological complications & $2.5 \%$ & $2.2 \%$ & 0.07 \\
\hline ICU stay [days] & $3.1 \pm 5.9$ & $3.5 \pm 5.8$ & 0.00 \\
\hline Hospital stay [days] & $9.9 \pm 7.9$ & $10.1 \pm 8.1$ & 0.04 \\
\hline
\end{tabular}

EF - ejection fraction, CCS - Canadian Cardiovascular Society, NYHA - New York Heart Association, BMI - body mass index, MI - myocardial infarction, $\mathrm{PCl}$ - percutaneous coronary intervention, COPD - chronic obstructive pulmonary disease, CVD - carotid vessel disease, PVD - peripheral vessel disease, NTG - nitroglycerine, IABP - intra-aortic balloon pump, ICU - intensive care unit.
Table II. Octogenarians without significant left main stenosis (no LMS) $(n=2094)$

\begin{tabular}{|c|c|c|c|}
\hline Parameter & $\begin{array}{c}\text { CABG } \\
(n=1107)\end{array}$ & $\begin{array}{c}\text { OPCAB } \\
(n=908)\end{array}$ & $\begin{array}{l}\text { MIDCAB } \\
(n=79) \\
\end{array}$ \\
\hline Age & $81.6 \pm 1.9$ & $81.9 \pm 7.3$ & $83.3 \pm 3.5$ \\
\hline Male sex & $38 \%$ & $38 \%$ & $49 \%$ \\
\hline $\mathrm{EF}(\%)$ & $49.8 \pm 10.2$ & $50.3 \pm 10.4$ & $49.5 \pm 9.9$ \\
\hline EuroSCORE & $3.1 \pm 4.04$ & $3.0 \pm 3.3$ & $3.8 \pm 4.5$ \\
\hline CCSI & $10 \%$ & $7 \%$ & $16.5 \%$ \\
\hline $\operatorname{CCS} \|$ & $31 \%$ & $32 \%$ & $39.2 \%$ \\
\hline CCS III & $45 \%$ & $43 \%$ & $41.8 \%$ \\
\hline CCS IV & $14 \%$ & $17 \%$ & $2.5 \%$ \\
\hline NYHA I & $41 \%$ & $41 \%$ & $59.5 \%$ \\
\hline NYHA II & $43 \%$ & $45 \%$ & $24.1 \%$ \\
\hline NYHA III & $14 \%$ & $14 \%$ & $16.5 \%$ \\
\hline NYHA IV & $2 \%$ & $12 \%$ & $0.0 \%$ \\
\hline BMI & $27.2 \pm 3.8$ & $26.8 \pm 3.5$ & $27.4 \pm 4.7$ \\
\hline Previous MI & $66 \%$ & $62 \%$ & $58 \%$ \\
\hline Previous $\mathrm{PCl}$ & $20 \%$ & $25 \%$ & $43 \%$ \\
\hline Smoking & $39 \%$ & $48 \%$ & $22 \%$ \\
\hline Diabetes & $34 \%$ & $36 \%$ & $37 \%$ \\
\hline Arterial hypertension & $91 \%$ & $88 \%$ & $92 \%$ \\
\hline Hyperlipidaemia & $60 \%$ & $55 \%$ & $52 \%$ \\
\hline Renal insufficiency & $47 \%$ & $48 \%$ & $56 \%$ \\
\hline COPD & $5 \%$ & $8 \%$ & $2.5 \%$ \\
\hline Atrial fibrillation & $11 \%$ & $13 \%$ & $13.9 \%$ \\
\hline CVD & $40 \%$ & $39 \%$ & $62.5 \%$ \\
\hline PVD & $95 \%$ & $89 \%$ & $86.7 \%$ \\
\hline Intravenous NTG/heparin & $13 \%$ & $13 \%$ & $6.3 \%$ \\
\hline Inotropic support & $2 \%$ & $1.4 \%$ & $0.0 \%$ \\
\hline Mechanical ventilation & $1 \%$ & $0.2 \%$ & $0.0 \%$ \\
\hline Cardiogenic shock & $0.5 \%$ & $0.8 \%$ & $1.3 \%$ \\
\hline Preoperative IABP & $2 \%$ & $1.3 \%$ & $1.3 \%$ \\
\hline $\begin{array}{l}\text { No. of narrowed coronary } \\
\text { arteries }\end{array}$ & $2.6 \pm 0.7$ & $2.0 \pm 0.9$ & $1.07 \pm 0.3$ \\
\hline No. of venous grafts & $1.9 \pm 0.8$ & $1.0 \pm 0.9$ & $0.04 \pm 0.2$ \\
\hline No. of arterial grafts & $0.8 \pm 0.5$ & $1.0 \pm 0.5$ & $1.03 \pm 0.1$ \\
\hline In-hospital mortality & $7 \%$ & $4.7 \%$ & $5.1 \%$ \\
\hline Bleeding (reoperation) & $6.6 \%$ & $3.6 \%$ & $6.3 \%$ \\
\hline Perioperative MI & $1.6 \%$ & $1.0 \%$ & $0.0 \%$ \\
\hline Haemodiafiltration & $3 \%$ & $2.8 \%$ & $2.5 \%$ \\
\hline Neurological complications & $3 \%$ & $1.9 \%$ & $0.0 \%$ \\
\hline Postoperative IABP & $3.5 \%$ & $1.7 \%$ & $1.3 \%$ \\
\hline ICU stay [days] & $3.3 \pm 6.6$ & $2.3 \%$ & $2.5 \%$ \\
\hline Hospital stay [days] & $10.3 \pm 8.5$ & $3.0 \pm 6.0$ & $3.3 \pm 4.1$ \\
\hline
\end{tabular}

EF-ejection fraction, CCS - Canadian Cardiovascular Society, NYHA - New York Heart Association, BMI - body mass index, $\mathrm{MI}$ - myocardial infarction, $\mathrm{PCl}$ percutaneous coronary intervention, COPD - chronic obstructive pulmonary disease, CVD - carotid vessel disease, PVD - peripheral vessel disease, NTG nitroglycerine, IABP - intra-aortic balloon pump, ICU - intensive care unit. 


\section{Statistical analysis}

Quantitative parameters are represented by their mean value and its standard deviation, and categorical data are represented by percentages. The distribution of quantitative variables was tested using the Shapiro-Wilk test. Due to non-normal distributions, the comparisons between parameters in individual groups were performed using the Mann-Whitney $U$ test. Discrete parameters were evaluated using the $\chi^{2}$ test.

The PS model included the following 28 preoperative variables: age, gender (male/female), body mass index, EuroSCORE, LVEF, previous myocardial infarction, previous PCI, angina (Canadian Cardiovascular Society (CCS) I-IV), functional classification (New York Heart Association (NYHA) I-IV), diabetes, smoking history, arterial hypertension, hyperlipidaemia, renal insufficiency, atrial fibrillation, mean number of significantly stenosed main coronary arteries and preoperative status (intravenous nitroglycerine and/or heparin, inotropic support, cardiogenic shock, preoperative IABP, mechanical ventilation). Data were matched with the greedy data matching procedure, using the Mahalanobis distance calculation method including the PS. Calliper radius was set to $0.2^{\star}$ sigma.

The Kaplan-Meier estimator and the Cox proportional hazards model were used for long-term survival analysis. Multivariate analysis was performed for all patients. In the first step, a multivariate analysis that included all the data was performed, and then the automatic stepwise method was used to reduce the model. CCS I and NYHA I classes were used as references.

All hypotheses were assumed to be bilaterally verified by bilateral tests. A $p<0.05$ was considered statistically significant. Statistical analysis was performed using the Statistica software package (StatSoft Inc., Palo Alto, CA).

Due to the significant differences between the groups, PS matching was used to create two homogeneous groups operated off-pump and on-pump. Comparative analysis of PS patients showed no differences in perioperative status of the patients between the groups.

Multivariate analysis allowed us to determine factors that affect long-term survival. The absence of a variable describing the type of surgery indicates that the method of operation does not affect late survival.

\section{Results}

The patients in both groups (no-LMS vs. LMS) showed no-significant variability with a history of smoking, diabetes, hypertension and hypercholesterolaemia, but in the LMS group there were more frequent instances of previous myocardial infarction (70\% vs. $64 \% ; p<0.001)$ and acute myocardial infarction ( $46.7 \%$ vs. $37.8 \% ; p<0.001)$. The LMS patients often had unstable angina (defined as angina requiring intravenous infusions of nitroglycerine and/or heparin), preoperative IABP and mechanical ventilation in a critical state ( $4.9 \%$ vs. $2.4 \% ; p<0.001)$, in
Table III. Octogenarians with significant left main stenosis (LMS) $(n=1524)$

\begin{tabular}{|c|c|c|c|}
\hline Parameter & $\begin{array}{c}\text { CABG } \\
(n=891)\end{array}$ & $\begin{array}{l}\text { OPCAB } \\
(n=616)\end{array}$ & $\begin{array}{l}\text { MIDCAB } \\
(n=17)\end{array}$ \\
\hline Age & $82.1 \pm 2.0$ & $82.3 \pm 2.3$ & $82.5 \pm 2.4$ \\
\hline Male sex & $32 \%$ & $33 \%$ & $41 \%$ \\
\hline $\mathrm{EF}(\%)$ & $48.2 \pm 11.5$ & $48.2 \pm 11.0$ & $48.5 \pm 11.2$ \\
\hline EuroSCORE & $4.04 \pm 5.7$ & $4.4 \pm 6.6$ & $4.1 \pm 2.5$ \\
\hline CCSI & $5.6 \%$ & $4 \%$ & $0.0 \%$ \\
\hline $\operatorname{CCS} \|$ & $23 \%$ & $21 \%$ & $17.6 \%$ \\
\hline CCS III & $39 \%$ & $45 \%$ & $52.9 \%$ \\
\hline CCS IV & $32 \%$ & $30 \%$ & $29.4 \%$ \\
\hline NYHA I & $37 \%$ & $37 \%$ & $35.3 \%$ \\
\hline NYHA II & $40 \%$ & $40 \%$ & $52.9 \%$ \\
\hline NYHA III & $17 \%$ & $17 \%$ & $11.8 \%$ \\
\hline NYHA IV & $6 \%$ & $19 \%$ & $0.0 \%$ \\
\hline $\mathrm{BMI}$ & $26.7 \pm 3.6$ & $26.8 \pm 3.6$ & $24.8 \pm 2.5$ \\
\hline Previous MI & $71 \%$ & $69 \%$ & $71 \%$ \\
\hline Previous PCl & $18 \%$ & $16 \%$ & $47 \%$ \\
\hline Smoking & $38 \%$ & $52 \%$ & $59 \%$ \\
\hline Diabetes & $31 \%$ & $37 \%$ & $53 \%$ \\
\hline Arterial hypertension & $90 \%$ & $89 \%$ & $88 \%$ \\
\hline Hyperlipidaemia & $56 \%$ & $61 \%$ & $41 \%$ \\
\hline Renal insufficiency & $42 \%$ & $48 \%$ & $64 \%$ \\
\hline COPD & $8 \%$ & $7 \%$ & $17.6 \%$ \\
\hline Atrial fibrillation & $10 \%$ & $12 \%$ & $11.8 \%$ \\
\hline CVD & $46 \%$ & $42 \%$ & $50.0 \%$ \\
\hline PVD & $93 \%$ & $93 \%$ & $66.7 \%$ \\
\hline Intravenous NTG/heparin & $24 \%$ & $25 \%$ & $11.8 \%$ \\
\hline Inotropic support & $3 \%$ & $4.0 \%$ & $0.0 \%$ \\
\hline Mechanical ventilation & $1 \%$ & $0.7 \%$ & $0.0 \%$ \\
\hline Cardiogenic shock & $2 \%$ & $1.5 \%$ & $0.0 \%$ \\
\hline Preoperative IABP & $5 \%$ & $2.5 \%$ & $0.0 \%$ \\
\hline $\begin{array}{l}\text { No. of narrowed coronary } \\
\text { arteries }\end{array}$ & $2.7 \pm 0.7$ & $2.1 \pm 0.9$ & $1.18 \pm 0.5$ \\
\hline No. of venous grafts & $2.0 \pm 0.8$ & $1.1 \pm 0.9$ & $0.18 \pm 0.5$ \\
\hline No. of arterial grafts & $0.7 \pm 0.5$ & $1.0 \pm 0.6$ & $1.00 \pm 0.0$ \\
\hline In-hospital mortality & $10.5 \%$ & $6.2 \%$ & $5.9 \%$ \\
\hline Bleeding (reoperation) & $7.1 \%$ & $4.9 \%$ & $5.9 \%$ \\
\hline Perioperative MI & $2 \%$ & $1.0 \%$ & $5.9 \%$ \\
\hline Haemodiafiltration & $4 \%$ & $5.0 \%$ & $5.9 \%$ \\
\hline Neurological complications & $2.8 \%$ & $1.5 \%$ & $0.0 \%$ \\
\hline Postoperative IABP & $7.5 \%$ & $1.8 \%$ & $0.0 \%$ \\
\hline ICU stay [days] & $3.4 \pm 6.5$ & $4.7 \%$ & $0.0 \%$ \\
\hline Hospital stay [days] & $10.5 \pm 9.0$ & $3.2 \pm 4.7$ & $2.6 \pm 1.5$ \\
\hline
\end{tabular}

EF-ejection fraction, CCS - Canadian Cardiovascular Society, NYHA - New York Heart Association, BMI - body mass index, $\mathrm{MI}$ - myocardial infarction, $\mathrm{PCl}$ percutaneous coronary intervention, COPD - chronic obstructive pulmonary disease, CVD - carotid vessel disease, PVD - peripheral vessel disease, NTG nitroglycerine, IABP - intra-aortic balloon pump, ICU - intensive care unit. 
Table IV. Mortality in group 80+ after coronary operations

\begin{tabular}{|c|c|c|c|c|}
\hline Researchers, country [ref.] & Years & Numbers & Age & Mortality \% \\
\hline Tsai et al., China [17] & 1982-1992 & 305 & $>80$ & CABG 8.3 \\
\hline Curtis et al., USA [18] & 1981-1994 & 68 & $>80$ & CABG 14.7 \\
\hline Fruitman et al., Canada [22] & 1.03.1995-28.02.1997 & 127 & $>80$ & CABG 7.9 \\
\hline Hirose et al., Japan [21] & $1.01 .1992-31.08 .2000$ & 55 & $>80$ & OPCAB 2.5 \\
\hline Kozlow et al., [23] & $2000-2003$ & 35761 & $>80$ & CABG 6.5 \\
\hline Wieintraub et al., USA [2] & 1.01.2004-31.12.2008 & 86244 & $>65$ & $\begin{array}{c}\text { OPCAB vs. } \mathrm{PCl} \\
1 Y-6.24 \text { vs. } 6.25 \\
4 Y-16.4 \text { vs. } 20.8\end{array}$ \\
\hline GOPCABE trial, Germany [2] & $25.06 .2008-9.09 .2011$ & 2394 & $>75$ & OPCAB 3.0 \\
\hline $\begin{array}{l}\text { Pawlaczyk et al., } 14 \text { multicenter } \\
\text { analysis [3] }\end{array}$ & 2000-2011 & 4991 & $>80$ & $\begin{array}{l}\text { OPCAB } 3.8 \\
\text { CABG } 6.0\end{array}$ \\
\hline $\begin{array}{l}\text { Kowalczuk-Wieteska et al., } \\
\text { KROK Base, Poland }\end{array}$ & $1.01 .2006-31.12 .2016$ & 3648 & $>80$ & $\begin{array}{c}\text { OPCAB LMS } \\
6.2 \text { vs. } 4.7 \\
\text { CABG LMS } \\
10.5 \text { vs. } 7.0 \\
\text { MIDCAB LMS } \\
5.9 \text { vs. } 5.1 \\
\end{array}$ \\
\hline Hoffmann et al., Germany [4] & 1998-2012 & 1060 & $>80$ & MIDCAB 5.5 \\
\hline
\end{tabular}

cardiogenic shock $(1.7 \%$ vs. $0.6 \%$; $p<0.001)$, with IABP (3.9\% vs. $1.9 \% ; p<0.001)$, or with inotropic drugs $(3.5 \%$ vs. $1.3 \% ; p<0.001)$. LMS patients were more often operated on in urgent situations ( $53.6 \%$ vs. $48.1 \% ; p=0.02)$, in emergency $(12.9 \%$ vs. $4.2 \% ; p<0.001)$, and salvage mode $(2.8 \%$ vs. $0.5 \% ; p<0.001)$. Operative risk according to EuroSCORE among LMS patients was significantly higher $(6.14 \pm 4.2$ vs. $3.75 \pm 3.13$; $p<0.001)$.

The subgroups were separated, depending on the kind of the operation technique according to: CABG ( $n=$ 1107 vs. 891), off-pump coronary artery bypass (OPCAB) ( $n=908$ vs. 616$)$, and MIDCAB ( $n=79$ vs. 17$)$ methods.

Mean ECC and aortic cross-clamping time in the LMS group was longer at $80 \pm 39 \mathrm{~min}$ vs. $73 \pm 30 \mathrm{~min}$. The mean number of grafts was lower in the no-LMS group $(2.3 \pm 0.9$ vs. $2.44 \pm 0.8$; $p<0.001$ ); however, the average number of arterial grafts was significantly higher ( $0.87 \pm 0.51$ vs. 0.81 $\pm 0.56 ; p<0.001$ ).

Analysis of the entire cohort showed that LMS surgery was associated with fewer postoperative complications. The LMS group had fewer incidences of multi-organ failure (3.8\% vs. $1.8 \%$; $p<0.001)$, in particular with CABG $(5.1 \%$ vs. $1.7 \% ; p<0.001)$; renal failure with haemodiafiltration rate $(0.5 \%$ vs. $3.0 \% ; p=0.02)$, and respiratory complications ( $8.3 \%$ vs. $6.3 \% ; p=0.02)$. The ICU hospitalization in the LMS group was significantly longer.

The in-hospital mortality was significantly higher in the LMS group with CABG $(10.5 \%$ vs. $7.0 \% ; p=0.01)$, non-significant in OPCAB ( $5.1 \%$ vs. $5.7 \% ; p=0.78)$ and MIDCAB (5.9\% vs. 5.1\%; $p=0.64$ ). Long-term survival (10year, all-cause death) was significantly higher in the no-
LMS group ( $21.2 \%$ vs. $27.5 \%$; $p<0.001)$. Long-term survival (10-year, all-cause death) in the matched groups did not show a statistically significant difference (Figure $2 \mathrm{~A}-\mathrm{E}$ ).

The mean entire cohort follow-up was $3.4 \pm 2.7$ vs. $3.7 \pm 2.8$ years $(p<0.001)$. During follow-up $25.7 \%$ of patients in the LMS group, and $25.4 \%$ in the on-pump group died $(p=0.51)$. The data after PS were respectively: $24.3 \%$ vs. $25.6 \%(p=0.28)$ and mean follow-up was $3.4 \pm 2.7$ vs. $3.5 \pm 2.7$ years $(p=0.2)$.

\section{Discussion}

Over the last three decades, many authors have pointed to the role of elderly patients as an important and independent factor that predisposes to serious postoperative complications and increased mortality. There are numerous meta-analyses that have compared results of CABG and OPCAB in octogenarians, but data from randomized studies regarding this issue in elderly patients with left main stenosis have not been published yet in available medical literature. For several decades, CABG has been considered a standard treatment for significant left main disease. In the ASCERT Trial (2004-2008), the prevalence of cardiac surgery for LMS over PCI was associated with a lower risk of restenosis, and improved survival regardless of the presence of stenosis [5-12].

Among the patients 65 years of age, or older, who had two-vessel or three-vessel coronary artery disease without acute myocardial infarction, 86.24 underwent CABG and 103.55 underwent PCl. The median follow-up period was 2.67 years. After 1 year, there was no significant difference in adjusted mortality between the groups 
A

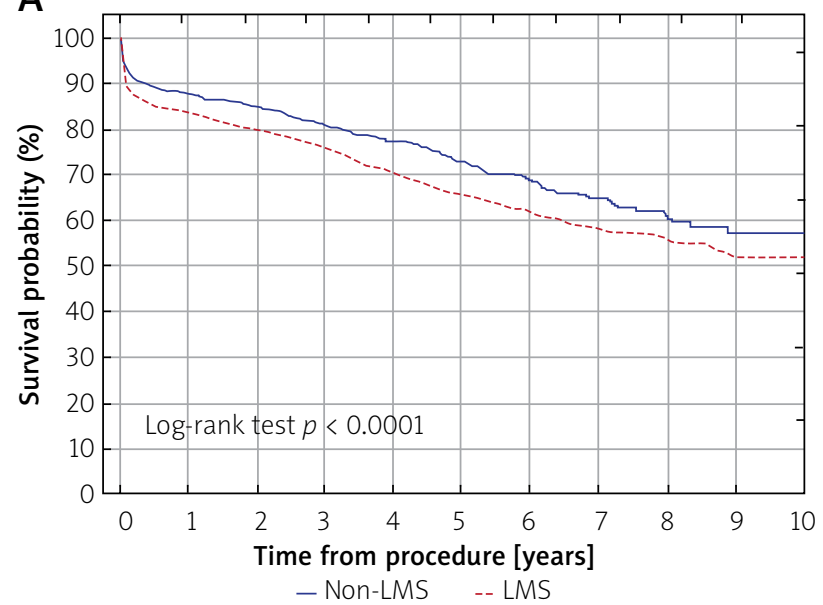

C

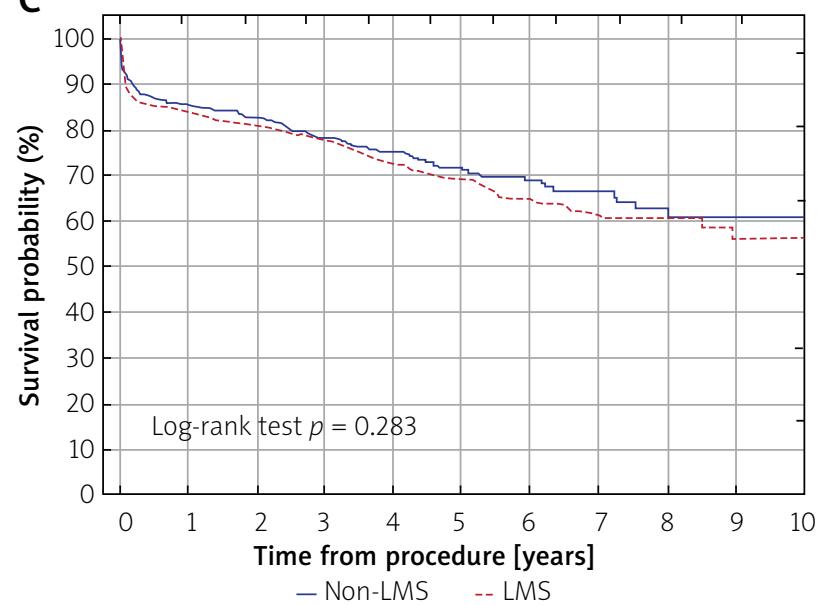

$\mathrm{E}$

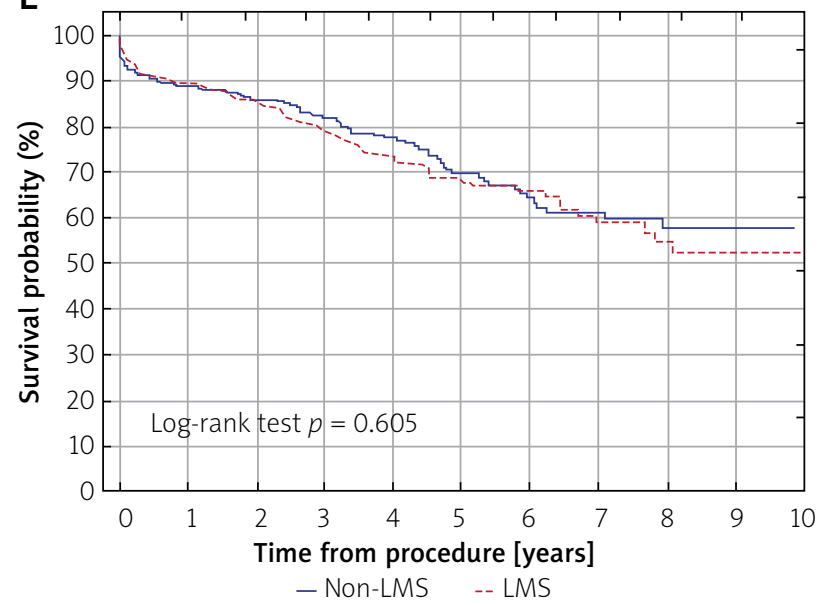

B

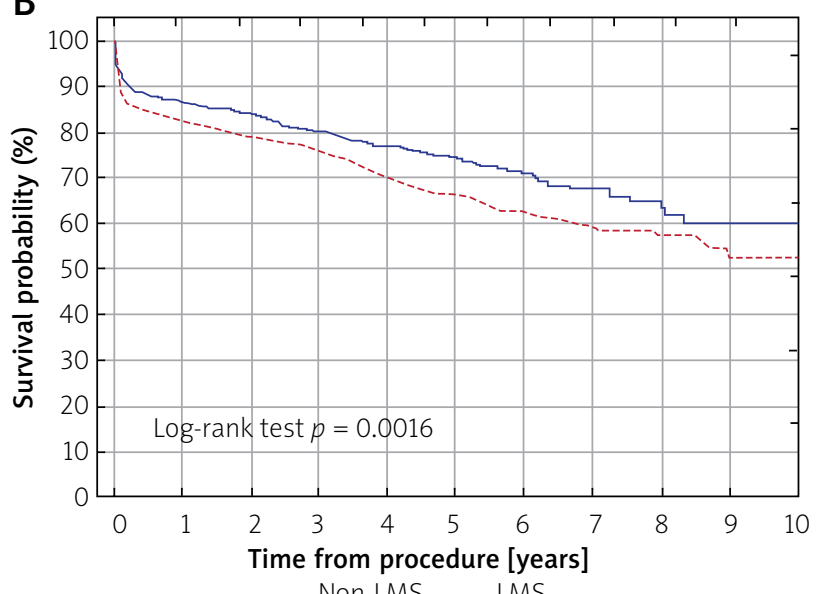

- Non-LMS -- LMS

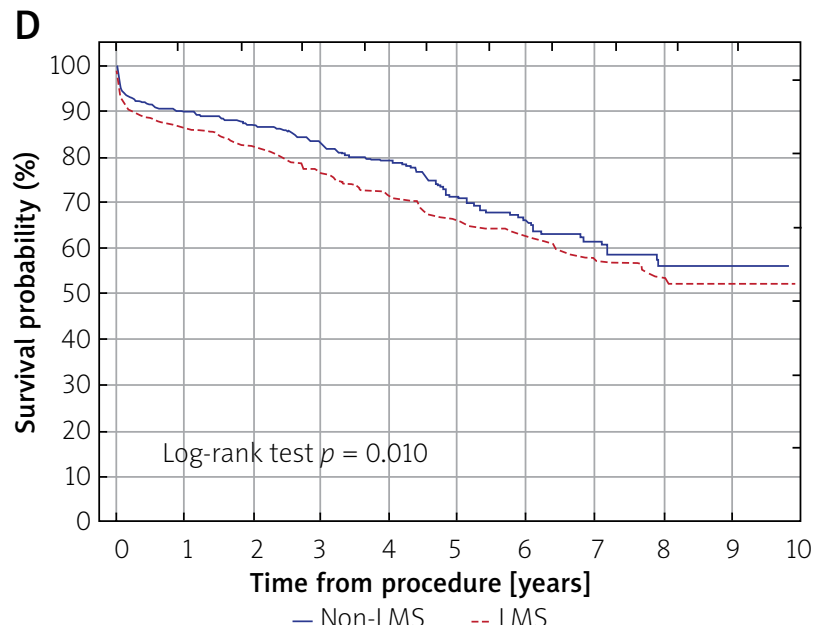

$\mathrm{F}$

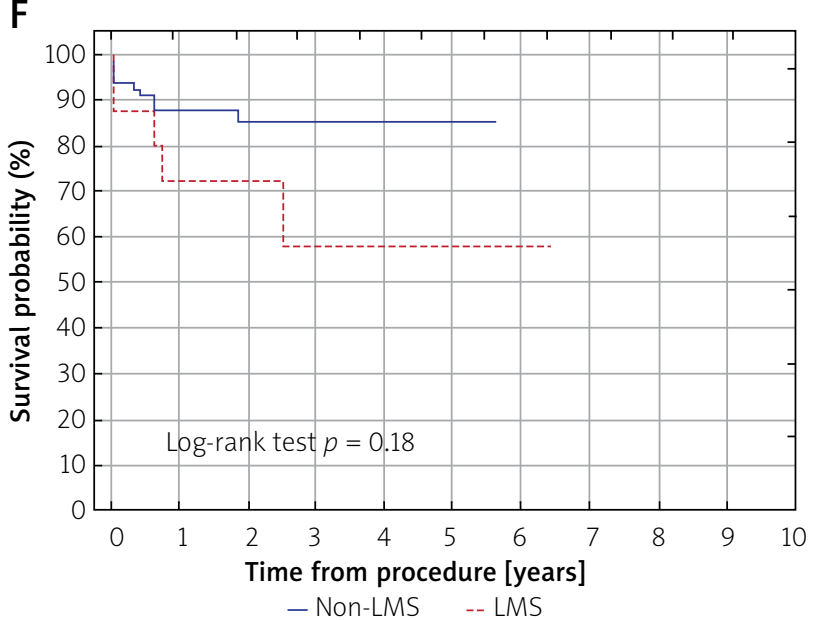

Figure 2. A - Survival probability in all patients $80+$ with no-LMS vs. LMS. B - Survival probability in nonmatched patients $80+$ with no-LMS vs. LMS after CABG. C - Survival probability in matched patients $80+$ with no-LMS vs. LMS after CABG. D - Survival probability in unmatched patients $80+$ with no-LMS vs. LMS after OPCAB. E - Survival probability in matched patients $80+$ with no-LMS vs. LMS after OPCAB. F - Survival probability in unmatched patients $80+$ with no-LMS vs. LMS after MIDCAB 
(6.24\% in the CABG group as compared with $6.55 \%$ in the $\mathrm{PCl}$ group; risk ratio: 0.95 ; $95 \%$ confidence interval (CI): 0.90-1.00). After four years, there was a lower mortality rate with CABG than with $\mathrm{PCl}(16.4 \%$ vs. $20.8 \%$; risk ratio; 0.79; 95\% Cl: 0.76-0.82) [13-18].

Pawlaczyk et al. analyzed 14 selected observational studies published between 2000 and 2011, comparing CABG and OPCAB techniques in octogenarians with LMS and without LMS [3]. The total number of included subjects was 0.99 , with 3.11 who underwent conventional CABG surgery (62.4\%), and 1.88 (37.6\%) who underwent off-pump CABG surgery. The rates of mortality (CABG $6 \%$ vs. OPCAB $3.8 \%$ ), stroke, and respiratory failure were significantly higher in the conventional CABG surgery group. In our material, patients after CABG - matched and unmatched - had significantly more frequent multi-organ complications and perioperative IABP, as well as a high percentage of in-hospital deaths (10.5\% vs. 7.0\%) [13-16, 19, 20].

It should be kept in mind that patients were frequently operated on in the urgent mode, on inotropic drugs, nitrates, or IABP at the terminal or cardiogenic shock. In our study, the mortality rate in the OPCAB method was $6.2 \%$ vs. $4.7 \%$. This is worse than in the case of Hirose et al. $(2.5 \%)$ or the GOPCABE trial (3\%), but it should be added that in the case of the group studied by Hirose et al., the number was low, $n=55$, and in the GOPCABE study, the study group was younger $>75$ years old. In both cases, it was not an isolated left coronary artery disease $[2,21]$.

In our MIDCAB study, a small number of patients were operated on, $n=79$, without LMS vs. 17 with LMS, so matching was impossible. Perioperative mortality was $5.9 \%$ vs. $5.1 \%$. The results are comparable to the Hoffmann et al. reports among 1060 octogenarians, between 1998 and 2012 [4]. Within 30 days, octogenarians showed a mortality rate of $5.6 \%$ (younger patients $0.8 \%$, $p=0.006$ ) and an MACCE rate of $5.6 \%$ (younger patients $1.3 \%, p=0.024)$. The median follow-up time of 30-day survivors was $5.5(2.9-7.6)$ years, and follow-up completeness reached $96.9 \%$. In the elderly group, 1-, 3- and 5 -year survival rates were 89,78 and $63 \%$ in comparison to 97,94 , and $90 \%$ in the younger group ( $p<0.001$ ). Ten-year survival in all subgroups was comparable and remained at a level of 50-60\%. The mean entire cohort follow-up was $3.4 \pm 2.7$ vs. $3.7 \pm 2.8$ years $(p=0.2)$ [4].

There is an ongoing debate concerning the best approach for myocardial revascularization in elderly patients with LMS stenosis. Some studies postulate that percutaneous coronary intervention is probably the method of choice, because of a lower risk of post-procedural complications.

In the review performed in large cohorts of octogenarians by McKellar et al., the 30-day mortality after CABG was $7.2 \%$, whereas after percutaneous coronary intervention it reached $5.4 \%$. In our meta-analysis, it was found that cumulative hospital mortality after OPCAB surgery was $6.2 \%$ vs. $4.7 \%$, and after MIDCAB surgery it was $5.9 \%$ vs. $5.1 \%$. These results cannot be compared directly, but they require our attention.

More complex atherosclerotic lesions and severe calcifications often present in octogenarian coronary arteries can be the reason why percutaneous coronary intervention is more likely to be unsuccessful when compared with a younger cohort. It seems that OPCAB or MIDCAB in elderly patients with LMS may have many advantages, as compared not only with CABG but also with percutaneous coronary intervention treatment [21-25].

\section{Suggested directions for the procedure in octogenarians with LM disease}

Choosing the right method of revascularization in elderly patients with LM disease is not an easy task, especially in the absence of randomized multicentre trials in the $80+$ group. In the case of 80-year-olds burdened with many diseases, the decision should be taken by the Heart Team, which includes an interventional cardiologist, a cardiac surgeon, an anaesthesiologist, but also a neurologist, diabetologist or geriatrician. The task of the group that creates this team is to create the most convenient conditions for invasive treatment in order to minimize the risk of perioperative complications [1].

Because the prognosis and the risk of major adverse cardiac and cerebrovascular events (MACCE) complications depend on the location of the lesion in LM, its location within the distal segment and division is usually a direct argument for CABG. It is also important to estimate the severity of atherosclerosis in the coronary arteries. Based on the SYNTAX study, it is known that the more comprehensive the changes are, the better are the results achieved by deciding on CABG (as compared to percutaneous transluminal coronary angioplasty (PTCA)). This argument should also be taken into account by the team deciding on the invasive treatment method. It should be remembered that the best long-term results are left intramammary artery-left coronary artery (LIMA-LAD) arterial bypass, which should be performed as soon as there are no absolute contraindications (e.g. lack of proper blood flow after LIMA dissection).

The choice of the treatment method is not decisive for a distant result as much as the patient's initial condition, his age, the burden of cardiovascular risk factors and additional diseases (including peripheral atherosclerosis, diabetes, significant obesity, chronic kidney disease or other structural heart diseases) and optimal pharmacotherapy.

\section{Study limitations}

Our study is a retrospective analysis and may have the shortcomings associated with analyses based on multicentre registry data. The impact on outcomes of centres that are less experienced in off-pump and MIDCAB 
revascularisation may be underestimated, especially in the scope of neurological complications.

\section{Conclusions}

Off-pump coronary bypass grafting may optimize the outcomes in elderly patients with significant left main stenosis. Octogenarians surgically treated for coronary artery disease, despite increased postoperative risks, present encouragingly long-term survival.

\section{Acknowledgments}

Special thanks to Mr. Daniel Cieśla for very diligent statistical work.

\section{Conflict of interest}

The authors declare no conflict of interest.

\section{References}

1. Wijns W, Kolh P, Danchin N, et al. Guidelines on myocardial revascularization. The task force on myocardial revascularization of the European Society of Cardiology (ESC) and the European Association for Cardio-Thoracic Surgery (EACTS). Eur Heart J 2010; 31: 2501-55.

2. Wieintraub WS, Grau-Sepulveda MV, Weiss JM, et al. Comparative effectiveness of revascularization strategies. N Engl J Med 2012; 366: 1467-76.

3. Pawlaczyk R, Swietlik D, Lango R, et al. Off-pump coronary surgery may reduce stroke, respiratory failure, and mortability in octogenarians. Ann Thorac Surg 2012; 94: 29-37.

4. Hoffmann G, Friedrich C, Barrabas M, et al. Short- and long-term follow-up after minimally invasive direct coronary artery bypass in octogenarians. Interact Cardiovasc Thorac Surg 2016; 23: 377-82.

5. Ricci M, Karamanoukian HL, Abraham R, et al. Stroke in octogenarians undergoing coronary artery surgery with and without cardiopulmonary bypass. Ann Thorac Surg 2000; 69: 1471-5.

6. Yokoyama T, Baumgartner FJ, Gheissari A, et al. Off-pump versus on-pump coronary bypass in high-risk subgroups. Ann Thorac Surg 2000; 70: 1546-50.

7. Demaria RG, Carrier M, Fortier S, et al. Reduced mortality and strokes with off-pump coronary artery bypass grafting surgery in octogenarians. Circulation 2002; 106 (12 Suppl 1): 15-10.

8. Hoff SJ, Ball SK, Coltharp WH, et al. Coronary artery bypass in patients 80 years and over: is off-pump the operation of choice? Ann Thorac Surg 2002; 74 (Suppl): S1340-3.

9. Beauford RB, Goldstein DJ, Sardari FF, et al. Multivessel of-pump revascularization in octogenarians: early and midterm outcomes. Ann Thorac Surg 2003; 76: 12-7.

10. Lin $\mathrm{CY}$, Hong GJ, Lee $\mathrm{KC}$, et al. Off-pump technique in coronary artery bypass grafting in elderly patients. ANZ I Surg 2003; 73 : 473-6.

11. Shimokawa T, Minato N, Yamada N, et al. Off-pump coronary artery bypass grafting in octogenarians. Jpn J Thorac Cardiovasc Surg 2003; 51: 86-90.

12. D'Alfonso A, Mariani MA, Amerini A, et al. Off-pump coronary surgery improves in-hospital and early outcomes in octogenarians. Ital Heart J 2004; 5: 197-204.
13. Serrao M, Graca F, Rodrigues $R$, et al. Cirurgia de revascularizacao miocardica em octogenarios: resultados a longo prazo [Coronary artery bypass grafting in octogenarians: long-term results]. Rev Port Cardiol 2010; 29: 989-98.

14. Saleh HZ, Shaw M, Fabri BM, et al. Does avoidance of cardiopulmonary bypass confer any benefits in octogenarians undergoing coronary surgery? Interact Cardiovasc Thorac Surg 2011; 12: 435-9.

15. LaPar DJ, Bhamidipai CM, Reece TB, et al. Is off-pump coronary artery bypass grafting superior to conventional bypass in octogenarians? J Thorac Cardiovasc Surg 2011; 141: 81-90.

16. Sarin EL, Kayatta MO, Kilgo P, et al. Short- and long-term outcomes in octogenarian patients undergoing off-pump coronary artery bypass grafting compared with on-pump coronary artery bypass grafting. Innovations (Phila) 2011; 6: 110-5.

17. Tsai TP, Chaux A, Matloff JM, et al. Ten-year experience of cardiac surgery in patients aged 80 years and over. Ann Thorac Surg 1994; 58: 445-51.

18. Curtis JJ, Walls JT, Boley T, et al. Coronary revascularization in the elderly: determinants of operative mortality. Ann Thorac Surg 1994; 58: 1069-72.

19. Nagpal AD, Bhatnagar G, Cutara CA, et al. Early outcomes of coronary artery bypass with and without cardiopulmonary bypass in octogenarians. Can J Cardiol 2006; 22: 849-53.

20. Tugtekin S, Kappert U, Alexiou K, et al. Coronary artery bypass grafting in octogenarians - outcome with and without extracorporeal circulation. Thorac Cardiovasc Surg 2007; 55: 407-11.

21. Hirose H, Amano A, Takahashi A. Coronary artery bypass grafting for octogenarians: experience in a private hospital and review of the literature. Ann Thorac Cardiovasc Surg 2001; 7: 282-91.

22. Fruitman DS, MacDougall CE, Ross DB. Cardiac surgery in octogenarians: can elderly patients benefit? Quality of life after cardiac surgery. Ann Thorac Surg 1999; 68: 2129-35.

23. Kozlov KL, Bogachev AA. Coronary revascularization in the elderly with stable angina. J Geriatr Cardiol 2015; 12: 555-68.

24. Rittger H. Interventional Cardiology in the Elderly. Springer International Publishing 2015.

25. Maruszewski B. National Registry of Cardiac Surgery (KROK) needed for patients treated with heart disease, healing and organizing treatment in Poland. Cardiac Surg Thorac Surg 2012; 2: 283. 